\title{
PELAKSANAAN MANUSA YADNYA DALAM UPACARA MELASTI PADA BAYI KEMBAR DI DESA PAKRAMAN BANYUSERI, KECAMATAN BANJAR, KABUPATEN BULELENG, BALI
}

\author{
I Putu Ari Sudiada \\ Ari9sudiada@gmail.com
}

\section{ABSTRAK}

\begin{abstract}
Penelitian ini bertujuan untuk mendapatkan gambaran tentang pelaksanaan Manusa Yadnya dalam Upacara Melasti pada bayi lahir kembar di Desa Pakraman Banyuseri tentang tahapan, proses dan nilai pendidikan yang terkandung didalamnya. Teknik pengumpulan data dilakukan melalui observasi, wawancara dan studi dokumen. Observasi dilaksanakan dengan cara melihat data-data dan terjun langsung di lokasi penelitian. Wawancara dilakukan secara mendalam terhadap informan yang paling mengetahui data yang dibutuhkan dalam hal ini PHDI, Pemangku, Penyuluh Agama Hindu serta tokoh masyarakat di Desa Pakraman Banyuseri yang dianggap mengetahui tentang masalah yang dikaji. Dan studi dokumen dilaksanakan dengan cara mempelajari pustaka-pustaka yang ada di Desa Pakraman Banyuseri. Hasil penelitian ini adalah tahapan yang ada dalam upacara Melasti pada bayi kembar ini, yaitu: Mekeet, Munpunin, Ngebug Kulkul Lan Metanding, Mapelawa, Nyiramang Due di Pura Taman, Ngunggahang Aci, Ngayah Nampah, Mapiuning Lan Memargi, Nyiramang Due Lan Sang Reged (Bayi Kembar dan Orang Tuanya), Ngayut Busana Sang Reged (Bayi Kembar dan Orang Tuanya) dan Ngaturang Bakti. Proses upacara Melasti pada bayi lahir kembar di Desa Pakraman Banyuseri merupakan tradisi sesuai Dresta yang dilaksanakan secara turun temurun. Upacara Melasti dilaksanakan dalam dua kategori yaitu apabila bayi lahir kembar biasa (kembar perempuan/laki-laki) Melasti dilaksanakan di Soan Alit. Sedangkan bayi yang lahir kembar Buncing, Melasti dilaksanakan di Soan Agung dan Soan Alit. Sarana yang digunakan yaitu menggunakan Banten Pengayatan pada saat nyiramang Duen Ida Bhatara, dan Banten Pejatian digunakan pada saat ngelukat bayi kembar dan kedua orang tuanya. Upacara Melasti pada bayi lahir kembar, yaitu: sebagai media pensucian Niasa (linggih) Ida Bhatara yang berstana di Desa Pakraman Banyuseri. Dan secara keseluruhan nilai pendidikan yang terkandung disetiap tahapan Manusa Yadnya dalam Upacara Melasti pada bayi lahir kembar ini adalah nilai kebersamaan, toleransi, tatakrama dan kesadaran diri (self awareness).
\end{abstract}

\section{ABSTRACT}

This study aims to get an overview of the implementation of Manusa Yadnya in the Melasti Ceremony on twins born in Pakraman Banyuseri Village about the stages, processes and values of education contained in it. Data collection techniques are carried out through observation, interviews and document studies. Observations were carried out by looking at the data and going directly to the research location. Interviews were carried out in depth to the informants who most knew the data needed in this case PHDI, Pemangku, Hindu Religious Extension and community leaders in Pakraman Banyuseri Village who were considered to know about the problem being studied. And document studies are carried out by studying the libraries in Pakraman Banyuseri Village. The results of this study are the stages that exist in the Melasti ceremony in these twins, namely: Mekeet, Munpunin, Ngebug 
Jurnal Widya Sastra Pendidikan Agama Hindu, Vol 4, No. 1, 2021

ISSN: 2656-7466

Kulkul Lan Metanding, Mapelawa, Nyiramang Due di Pura Taman, Ngunggahang Aci, Ngayah Nampah, Mapiuning Lan Memargi, Nyiramang Due Lan Sang Reged ( Twin Babies and Their Parents), Ngayut Busana Sang Reged (Twins and Parents) and Ngaturang Bakti. The Melasti ceremony process in twins born in Pakraman Banyuseri Village is a tradition according to the Dresta which is carried out for generations. The Melasti ceremony is carried out in two categories, namely if the ordinary twin babies (female / male twins) Melasti is carried out in Soan Alit. While babies born with Buncing twins, Melasti are held in Soan Agung and Soan Alit. The ingredients used were using Banten Pengayatan when nyiramang Duen Ida Bhatara, and Banten Pejenjang were used when holding twin babies and their parents. Melasti ceremony in twins is born, namely: as Niasa (linggih) purification media Ida Bhatara which is located in Pakraman Banyuseri Village. And overall the value of education contained in each stage of Manusa Yadnya in Melasti Ceremony in twins born is the value of togetherness, tolerance, manners and self awareness.

\section{PENDAHULUAN}

Keragaman tradisi ataupun kebudayaan yang dimiliki oleh suatu daerah menjadikan sebuah daya tarik tersendiri yang membedakannya dengan daerah yang lainnya. Budaya merupakan bagian dari kebiasaan masyarakat yang meliputi cara berbahasa, bergaul, bahkan dalam hal Yadnya. Dalam Yadnya, masyarakatpun mengenal tradisi yang berbedabeda. Tradisi tersebut merupakan warisan turun temurun dari para leluhur yang memiliki begitu banyak nilai-nilai didalamnya. Hal ini dikarenakan pada masyarakat tradisi itu masih sangat kuat dan kental, bahkan terkadang tradisi ini juga sangat mempengaruhi perkembangan suatu daerah. Keragaman budaya yang ada di suatu daerah telah melahirkan pula keragaman wujud-wujud kebudayaan. Diantaranya adalah adat istiadat, upacara-upacara agama, dan juga tradisi yang masih tetap dilestarikan oleh masyarakat.

Melasti dalam Babad Bali, disebutkan merupakan rangkaian dari Hari Raya Nyepi dan Melasti juga disebut juga Melis atau Mekiyis bertujuan untuk melebur segala macam kekotoran pikiran, perkataan dan perbuatan, serta memperoleh air suci (Angemet Tirta Amerta) untuk kehidupan yang pelaksanaannya dapat dilakukan di laut, danau, dan pada sumber/mata air yang disucikan.Pelaksanaan upacara Melasti disebutkan dalam lontar Sundarigama seperti ini:

"Manusa Kabeh Angaturaken Prakerti Ring Prawatek Dewata."

Artinya agar mengingatkan umat untuk terus mengingat dan meningkatkan bhaktinya kepada Tuhan (Artawijaya, 2010).

Masyarakat Desa Banyuseri memiliki pandangan terhadap beberapa hal yang dapat menyebabkan kekotoran (Reged) pada desa, yang diantaranya disebabkan oleh dua faktor yaitu kelahiran dan kematian. Bayi yang lahir normal (tidak kembar) dianggap membawa kekotoran dan pembersihannya cukup dengan menggunakan Banten Lis. Namun, jika bayi lahir kembar haruslah pembersihannya dilakukan dengan upacara Melasti yang bertepatan pada saat upacara Tutug Kambuhan pada bayi..

Pelaksanaan Upacara Melasti pada Bayi Lahir Kembar di Desa Banyuseri ini dilaksanakan berdasarkan Dresta secara turun temurun. Upacara ini dilaksanakan karena masyarakat Desa Banyuseri meyakini bahwa bayi yang lahir kembar membawa kekotoran bagi desa. Jika dilihat dari konsep Panca Yadnya yaitu Dewa Yadnya, Pitra Yadnya, Rsi Yadnya, Manusa Yadnya, dan Bhuta Yadnya, maka pelaksanaan upacara Melasti tersebut tergolong kedalam Dewa Yadnya dan Manusa Yadnya. 
Jurnal Widya Sastra Pendidikan Agama Hindu, Vol 4, No. 1, 2021

ISSN: 2656-7466

Berdasarkan latar belakang di atas, penulis tertarik untuk meneliti dan mengkaji lebih dalam mengenai Pelaksanaan Manusa Yadnya dalam Upacara Melasti pada Bayi Kembar di Desa Pakraman Banyuseri, Kecamatan Banjar, Kabupaten Buleleng (Perspektif Pendidikan Agama Hindu).

\section{PEMBAHASAN}

Desa Banyuseri terletak di Kecamatan Banjar, Kabupaten Buleleng, Bali. Wilayah Desa Banyuseri adalah suatu wilayah yang berada di Selatan dari pusat pasar Banjar, membentang dengan luas 3.250.000 M2. Jarak antara desa dengan kota Singaraja adalah $27 \mathrm{Km}$. Curah hujan di desa Banyuseri sangat tinggi yaitu sampai $30 \mathrm{~mm}$ karena berada di daerah pegunungan. Wilayah Desa Banyuseri

memiliki batas-batas, yaitu : 1) sebelah Barat berbatasan dengan Desa Tirtasari, 2) sebelah Timur berbatasan dengan Desa Pegentengan, 3) sebelah Utara berbatasan dengan Desa Perampas, 4) sebelah Selatan berbatasan dengan Desa Pedawa.

Masyarakat Desa Banyuseri dominan beragama Hindu (97\%) (Monografi Desa, tahun 2014:237). Realitas keagamaan, umat Hindu memang sangat tinggi terutama dalam melaksanakan kegiatan yang bersangkut paut dengan upacara keagamaan khususnya di bagian Parhyangan selalu di Laksanakan odalah Atau karya agung Pada Setiap Hari Raya, seperti: Galungan, Kuningan, Nyepi, Saraswati, Pagerwesi dan hari besar lainnya. Selain itu sering dilaksanakan persembanhyangan pada saat Purnama dan Tilem serta atusias warga sangat tinggi dalam setiap kegiatan keagamaan. Pada bagian Pawongan aktivitas warga saat Menyamabraya dalam hal ini ada sesama warga yang mempunyai upacara, sperti: Ngotonin, Melaspas, Kematian, Metatath, Pawiwahan dan Upacara Manusa Yadnya lainnya. Dan dibagian Palemahan juga nampak aktivitas warga yang selalu menjaga keharmonisan dan kelestarian lingkungan sangat tinggi. dengan adanya upacara Mecaru dan yang lainnya.

Upacara Melasti pada Bayi Lahir Kembar dilaksanakan berdasarkan drestha yang sudah secara turun temurun dilaksanakan oleh masyarakat Desa Pakraman Banyuseri. Nilai Pendidikan yang ada pada setiap pendidikannya adalah sebagai berikut.

Mekeet

Makeet maksudnya yaitu membuat rangkaian perlengkapan untuk sarana Upacara Melasti (majejaitan). Sebelum memulai ngaturang ayah (makeet) terlebih dahulu Jro Mangku Desa mapiuning di Pura Desa dan nunas pangresik kemudian dipercikkan kepada seluruh krama desa yang hadir. Setelah nunas pangresik, dane Saya memukul kulkul yang ada di Pura Desa. Setelah berbunyinya kulkul tersebut maka kegiatan Ngaturang ayah (Makeet) baru bisa mulai dilaksanakan. Nilai pendidikan yang ada pada tahapan ini adalah dimana kebersamaan harus selalu ada agar rasa saling membantu dan bekerjasama dapat dipertahankan. Hal ini sangat sejalan dengan Teori Humanistik yang dikemukakan oleh Carl Rogers, dimana Teori Humanistik adalah teori belajar yang memanusiakan manusia yang dalam hal ini manusia diminta untuk selalu peduli dan bekerjasama untuk mencapai suatu tujuan. Selain itu ada persiapan yang matang (planning) dalam setiap kegiatan dan keputusan ataupun kesepakatan harus ada dalam setiap perencanaan.

\section{Munpunin}

Mumpunin maksudnya yaitu membuat sarana untuk perlengkapan upacara melasti seperti membuat kelatkat, memotong ayam, dan sebagainya. Pada saat itu juga para truna-truni (Deha Truna), juru Gemblung atau yang bertugas memukul gong, Jro Ulu, dan Jro Penanggapan juga hadir di Pura Desa. Semua krama desa yang hadir pada saat itu ngaturang ayah sesuai dengan tugasnya masing-masing. Sebelum memulai ngaturang 
Jurnal Widya Sastra Pendidikan Agama Hindu, Vol 4, No. 1, 2021

ISSN: 2656-7466

ayah, Jro Mangku Desa mapiuning dan nunas pangresikan. Setelah selesai mapiuning dan nunas pangresikan, semua yang hadir pada saat itu menyiapkan diri untuk memulai aktivitas. Nilai pendidikan yang ada dalam tahapan ini adalah setiap kegiatan upacara agama wajib harus ada bahu membahu, kerjasama tolong menolong dan toleransi untuk mewujudkan suatu solidaritas satu dengan yang lain. Hal ini juga sangat sejalan dengan Teori Humanistik yang dikemukakan oleh Carl Rogers, dimana Teori Humanistik adalah teori belajar untuk selalu peduli dan bekerjasama untuk mencapai suatu tujuan tertentu. Selain itu harus ada aturan yang jelas dimana saat kegiatan persiapan upacara agama sangat tidak diperbolehkan berkata kasar ataupun menuturkan hal yang tidak benar. (wawancara tanggal 7 Oktober 2018).

\section{Ngebug Kulkul Lan Metanding}

Siang harinya tjam satu, acara di lanjutkan dengan Ngebug Kulkul yang tidak lain adalah giliran krama desa khususnya yang perempuan ngaturang ayah (matanding) ke Pura Desa. Matanding yaitu membuat banten-banten yang digunakan untuk rangkaian Upacara Melasti. Setelah selesai matanding, segala banten yang telah dibuat ditaruh di Pura Desa kemudian banten tersebut dijaga oleh juru saya. Nilai pendidikan yang ada pada tahap ini adalah setiap hal untuk memulai suatu upacara wajib ada suatu kesepakatan untuk mematuhi aturan yang ada dan tidak ada sedikitpun yang melanggar ketentuan yang ada. Dan terlihat juga ada nilai kerjasama dalam tahapan ini yang tampak pada hal ini adalah dimana adanya hukum yang mengatur bahwa setiap ada bunyi Kulkul seolah olah ada perberitahuan yang mengikat namun tidak memaksa sehingga hal ini sangat sejalan dengan teori Hegemoni oleh Gramsci yang menekankan kesadaran moral, dimana seseorang disadarkan lebih dulu akan tujuan hegemoni itu. Setelah seseorang sadar, ia tidak akan merasa dihegemoni lagi melainkan dengan sadar melakukan hal tersebut dengan suka rela. dan hal ini juga sangat sejalan dengan teori Stimulus Respons yang di kemukakan oleh Pavlov, kalau dibiasakan maka untuk kedepannya seseorang akan merasa bahwa itu adalah sebuah hal yang harus dilaksanakan sebagaimana pendapat yang dikemukakan oleh Pavlov mengenai eksperimen yang dilakukannya dan tentunya sangat ada dalam hal ini. Mapelawa

Mapelawa yaitu memasang dedaunan pada palinggih-palinggih dengan menggunakan Don Temen dan Don Biu Alas yang merupakan sebagai dasar persembahan kepada Ida Bhatara. Menurut penuturan Masyarakat, pada saat mapelawa tidak diperbolehkan untuk berbicara. Makna tidak boleh berbicara yaitu agar bisa fokus sehingga bisa memusatkan pikiran kepada pencipta alam semesta. Kata memusatkan pikiran sangat terkait dengan teori konsentrasi belajar yang diungkapkan oleh Daud yang menjelaskan bahwa konsentrasi belajar adalah pemusatan perhatian dalam proses perubahan tingkah laku yang dinyatakan dalam bentuk penguasaan. Dalam hal mapelawa ini pemusatan pikiran ditujukan kepada pencipta alam semesta sehingga terlihat jelas bahwa proses perubahan tingkah laku sangat ada dalm ini. Nilai pendidikan yang ada adalah setiap rangkaian kegiatan pasti ada persiapan yang matang. Mepelawa adalah bagian dari persiapan tersebut yang bisa diwariskan kepada generasi selanjutkan agar menyiapkan segala hal sebelum memulai suatau kegiatan di dalamnya harus ada nilai etika dan tatakrama. Kata Pelawa itu sendiri sangat terkait dengan teori simbul yang dikemukakan oleh Francis Abraham dimana suatu proses individu berinteraksi dengan menggunakan simbol-simbol yang bermakna.

\section{Nyiramang Due Di Pura Taman}

Setelah selesai Mapelawa kemudian para truna-truni (Deha Truna) berjalan (mamargi) untuk nyiramang Duen Ida Bhatara ke Pura Taman dan diikuti oleh Jro Mangku Taman. Segala perlengkapan seperti linggih Duen Ida Bhatara, Gong, Prasasti, Tumbak, Umbul-Umbul, Rontek dibawa menuju Pura Taman. Nilai pendidikannya adalah setiap hal yang dilaksanakan seharusnya 
Jurnal Widya Sastra Pendidikan Agama Hindu, Vol 4, No. 1, 2021

ISSN: 2656-7466

dilaksanakan dengan kesucian dan kebersiahan untuk menjaga suasana agar tetap nyaman. Di Dalamnya juga ada nilai partisipasi, etika dan tatakrama. Hal ini terkait dengan Teori Religi oleh Geertz, mengemukakan bahwa setiap hal yang berbaur keagamaan mengandung sistem yang kompleks dan terlihat jelas bahwa saat nyiramang due ini hal yang dimiliki oleh desa terlihat sangat kompleks.

\section{Ngunggahang Aci}

\section{Kegiatan selanjutnya yaitu Jro Ulu dan jro Penanggapan ngunggahang}

Aci. Aci merupakan suguhan yang dipersembahan kepada Ida Bhatara. Nilai pendidikan yang terdapat dalam tahapan ini adalah segala hal yang dipersembahkan harus berdasarkan keikhlasan. Hal ini sejalan dengan teori simbol yang dikemukakan oleh Francis Abraham, dimana Aci itu sendiri adalah simbol dari persembahan kehadapan Ida Bhatara. Dan wajib diberikan contoh oleh generasi tua sehingga Ulu dan Penaggapan yang berperan dalam hal ini agar mampu menularkan kepada generasi selanjutnya.

\section{Ngayah Nampah}

Keesokan harinya dipagi tjam 7, kembali lagi krama desa khususnya yang laki-laki ngaturang ayah (nampah celeng). Krama desa yang laki-laki mengerjakan sarana berupa guling yang dipergunakan untuk perlengkapan Upacara Melasti. Babi yang dipergunakan untuk pembuatan Guling diberikan oleh keluarga bayi kembar tersebut. Babi yang dipergunakan adalah babi yang berwarna hitam mulus dan tidak ada cacat sedikitpun. Nilai pendidikan dari tahapan ini adalah setiap orang wajib ada pengorbanan dalam setiap hal yang dilakukan. Apalagi dalam hal ini desa yang mengupacarai maka sebagai pihak yang dianggap terkena musibah harus ada timbal balik terhadap kegiatan tersebut sebagai bentuk terimakasih. Dengan adanya hubungan timbal balik maka tentunya Teori Stimulus Respons yang dikemukakan oleh Pavlov dimana untuk menimbulkan atau memunculkan reaksi yang diinginkan yang disebut respon, maka perlu adanya stimulus yang dilakukan secara berulang-ulang sehingga disebut dengan pembiasaan. Sama halnya dengan pihak yang mempunyai bayi kembar dengan adanya upacara tersebut maka yang bersangkutan sudah menjadi kebiasaan untuk memberikan babi sebagai sarana upacara bila tidak akan dianggap keluar dari aturan yang ada. Disamping itu juga ada nilai toleransi, partisipasi dan kerjasama.

\section{Mapiuning Lan Memargi}

Jro Mangku desa mapiuning untuk pemberitahuan akan melaksanakan Upacara Melasti ke lokasi yang ditetapkan. Selesai mapiuning, kemudian mapurwa di Pura Cetaan sebanyak tiga kali. Setelah itu, kembali mamargi ke Pura desa tepatnya di jabaan Pura Desa. Pada jaba tengah (jabaan) mapurwa sebanyak tiga kali. Acara selanjutnya menuju lokasi untuk melaksanakan Upacara Melasti. Linggih Ida Bhatara yang ditempatkan di pangogongan dan berada paling depan dan diikuti oleh krama desa di belakang. Nilai pendidikan dari tahapan ini adalah sebagai umat Hindu wajib menghormati alam yang ada khususnya sumber air yang dipercaya mampu membersihkan segala kotoran yang ada dalam diri manusia. Dan diawali dari kebenaran sehingga putarannya wajib ke kanan. Dari kepercayaan masyarakat terhadap sumber air tentunya sangat ada keterkaitan dengan teori Simbol oleh Francis Abraham dalam Modern Sociological Theory (1982) dimana suatu proses individu berinteraksi dengan dirinya sendiri dengan menggunakan simbol-simbol yang bermakna. Dengan hal

entunya makna yang terdapat dalam sumber air suci tersebut tidak lain adalah untuk membersihkan dan menyucikan sekala maupun niskala nya. Selain itu juga kegiatan yang 
Jurnal Widya Sastra Pendidikan Agama Hindu, Vol 4, No. 1, 2021

ISSN: 2656-7466

dilaksanakan wajib ada pemberitahuan dan piuning kepada Ida agar acara tersebut berjalan lancar. Kesenian, Kesucian, rasa bersyukur dan rasa bakti ada dalam tahapan ini.

Nyiramang Due Lan Sang Reged (Bayi Kembar Dan Orang Tuanya) Pada saat di Soan Agung (laut) ataupun Soan Alit (sungai), selanjutnya yaitu Nyiramang Duen Ida Bhatara pada sumber air yang tidak jauh dari area tempat Melasti. Seperti biasa sebelum mulai Nyiramang Duen Ida Bhatara jro Mangku desa mapiuning, barulah Nyiramang Duen Ida Bhaatara dilaksanakan. Selesai Nyiramang Duen Ida Bhatara, kembali menuju tempat Melasti, dan linggih Ida Bhatara ditempatkan pada laapan. Acara dilanjutkan dengan memandikan bayi kembar dan kedua orang tuanya. Bayi dan kedua orang tuanya mandi di sungai yang berada di samping area tempat Melasti. Nilai pendidikan yang ada pada tahapan ini adalah jangan hanya manusia saja yang harus dibersihkan benda-benda peninggalan leluhur yang masih disakralkan juga wajib disucikan sebagai bentuk rasa memiliki dan menghormati yang patut diwariskan untuk generasi selanjutnya. Dan juga setiap umat manusia tidak bisa lepas dari kebersamaan. Harus saling tolong menolong untuk mempersiapkan segala hal dalam menjalani kehidupan di dunia ini. Hal ini juga sangat sejalan dengan Teori Humanistik yang dikemukakan oleh Carl Rogers, dimana Teori Humanistik adalah teori belajar untuk selalu peduli dan bekerjasama untuk mencapai suatu tujuan tertentu. Kata tolong menolong yang ada dalam tahapan ini juga bagian dari kerjasama. Dan setiap memulai sesuatu harus berdasarkan doa yang tulus.

Sehingga nilai religius, partisipasi dan keikhlasan sangat berpengaruh dalam tahapan ini.

\section{Ngayut Busana Sang Reged (Bayi Kembar Dan Orang Tuanya)}

Pakaian yang tadinya dipergunakan dihanyudkan di sungai dan diganti dengan pakaian yang baru. Menghanyudkan pakaian dimaksudkan untuk membuang segala kekotoran yang melekat pada diri si bayi dan kedua orang tuanya. Nilai pendidikan yang terdapat pada tahapan ini adalah setiap hal yang dianggap kotor wajib dibersihkan dan disucikan dan setiap kehidupan harus ada pergantian untuk menuju hal yang lebih baik dan lebih bersih. Dari kepercayaan masyarakat terhadap ngayut busana orang tua bayi kembar begitu juga dengan busana sang bayi tentunya sangat ada keterkaitan dengan Teori Simbol oleh Francis Abraham dalam Modern Sociological Theory (1982) dimana suatu proses individu berinteraksi dengan dirinya sendiri dengan menggunakan simbol-simbol yang bermakna. Dengan hal itu tentunya makna yang terdapat dalam tahapan ini tidak lain adalah untuk membersihkan dan menyucikan sekala maupun niskala yang ada di desa Banyuseri. Toleransi, kerjasama dan kesadaran diri (self awareness) sangat berperan di dalamnya.

\section{Ngaturang Bakti}

Setelah acara pembersihan kepada bayi kembar dan kedua orang tuanya selesai, selanjutnya dilaksanakan Pangebaktian. Seluruh krama desa secara serentak melaksanakan persembahyangan. Nilai pendidikan yang terdapat pada tahap ini adalah setiapumat manusia harus selalu mendekatkan diri kehadapan Yang Kuasa. Hal ini sangat sejalan dengan Teori Humanistik yang dikemukakan oleh Carl Rogers, dimana Teori Humanistik adalah teori belajar untuk selalu

peduli dan bekerjasama untuk mencapai suatu tujuan tertentu disamping itu juga diajarkan untuk memanusiakan manusia. Dengan mendekatkan diri kehadapan Sang Maha Pencipta tentunya untuk mencapai kebaikan pasti bisa terpenuhi dengan kata lain memanusiakan manusia pasti dapat tercapai.

\section{PENUTUP}

Upacara Melasti pada bayi lahir kembar dilaksanakan berdasarkan drestha yang sudah secara turun temurun dilaksanakan oleh masyarakat Desa Banyuseri. Upacara Melasti pada 
Jurnal Widya Sastra Pendidikan Agama Hindu, Vol 4, No. 1, 2021

ISSN: 2656-7466

bayi lahir kembar dilaksanakan ketika bayi berumur 42 hari tepat pada Tutug kambuhan dan dalam dua kategori yaitu apabila bayi yang lahir kembar biasa (kembar perempuan maupun laki-laki) dalam pelaksanaan Upacara Melasti hanya dilaksanakan di Soan Alit karena membawa kekotoran lebih kecil bagi desa. Sedangkan bayi yang lahir kembar Buncing harus melaksanakan Upacara Melasti ke Soan Agung dan Soan Alit karena membawa kekotoran lebih besar bagi desa secara Sekala maupun Niskala.

Dari tahapan yang ada dimulai dari Mekeet, Munpunin, Ngebug Kulkul Lan Metanding, Mapelawa, Nyiramang Due di Pura Taman, Ngunggahang Aci, Ngayah Nampah, Mapiuning Lan Memargi, Nyiramang Due Lan Sang Reged (Bayi Kembar Dan Orang Tuanya), Ngayut Busana Sang Reged (Bayi Kembar Dan Orang Tuanya) dan Ngaturang Bakti dapat dijabarkan bahwa nilai pendidikan yang ada adalah dimana kebersamaan harus selalu ada agar rasa saling membantu dan bekerjasama dapat dipertahankan. Selain itu ada persiapan yang matang (planning) dalam setiap kegiatan dan keputusan ataupun kesepakatan harus ada dalam setiap perencanaan, setiap kegiatan upacara agama wajib harus ada bahu membahu, kerjasama tolong menolong dan toleransi untuk mewujudkan

suatu solidaritas satu dengan yang lain. Selain itu harus ada aturan yang jelas dimana saat kegiatan persiapan upacara agama sangat tidak diperbolehkan berkata kasar ataupun menuturkan hal yang tidak benar.

\section{DAFTAR PUSTAKA}

Arikunto, 2006. Teknik Pengumpulan Data Penelitian Lapangan. Surabaya. Paramita

Artawijaya. 2010. "Upacara Melasti (mekiyis) Dalam Perayaan Hari Raya Nyepi di Bali". http://catatanradiograf.blogspot.com. diunduh tanggal 26 Maret 2015

Basrowi dan Suwandi. 2008. Memahami Penelitian Kualitatif. Jakarta: Rineka Cipta.

Chahyawati, Dwi. 2013. “Aktualisasi Nilai-nilai Luhur Pancasila dalam Upacara Melasti”. Universitas Negeri Malang. http://karya-ilmiah.um.ac.id. diunduh tanggal 26 Maret 2015.

Daud. 2010. Penelitian Kualitatif. Surabaya: Paramita

Engkoswara. 2012. Pokok Antropologi Sosial. Jakarta: Dian Rian.

Dewa Made Tantera Keramas, Prof. Dr. 2008. Metoda Penelitian Kualitatif dalam IImu Agama dan Kebudayaan. Penerbit Paramita Surabaya.

Faruk. 1994. Metodologi Penelitian Sosial-Agama. PT. Remaja Rosdakarya: Bandung

Geertz, Clofford. 1995. Budayawan dan Agama. Yoyakarta: Penerbit Erlangga.

Gorda, I Gusti Ngurah. 1990. Metodologi Penelitian Ilmu Sosial Praktis.

Denpasar. Undiknas.

Gulo, W. 2004. Metode Penelitian. Jakarta: Pt Gramedia Widiarsana Indonesia.

Hamidi. 2005. Penelitian Kualitatif. Surabaya: Paramita.

Kamus Besar Bahasa Indonesia. 1991. Penerbit Jakarta Balai Pustaka. 
Jurnal Widya Sastra Pendidikan Agama Hindu, Vol 4, No. 1, 2021

ISSN: 2656-7466

Koentjaraningrat, 1990. Beberapa Pokok Antropologi Sosial. Jakarta: Dian Rian. 1996. Pengantar Antropologi. Jakarta: Rineka Cipta.

Maulana. 2011. Penelitian Kualitatif. Surabaya: Paramita

Moleong, lexy J. 2004. Metoda Penelitian Kualitatif. Penerbit: Remaja Rosdakarya.

Monografi Desa Banyuseri Tahun 2001 Remaja 2007. Metoda

Penelitian Kualitatif. Penerbit:

Rosdakarya.

Nasikum. 2003. Sistem Sosial Indonesia. Yogyakarta: Universitas Gajah Mada Press.

Nasution, S. 1996. Metode Penelitian Naturalistik Kualitatif. Bandung: Tarsito.

Netra, Ida bagus. 1976. Metodologi Penelitian. Penerbit: Fakultas IImu Pendidikan IKIP. Singaraja.

Penyuratan Drestha Desa Banyuseri.

Pergata. 2012. "Panca Yadnya". http://pergata.wordpres.com. diunduh tanggal 26 Maret 2015.

Poerwadarmita, 1995. Kamus Besar Bahasa Indonesia. Penerbit Jakarta Balai Pustaka.

Ratna. 2005. Teori Tentang Simbol. Jakarta: Gramedia

Sagala. 2011. Metodologi Penelitian IImu Sosial Praktis. Denpasar. Undiknas

Sarono, Prasetiyo Hadi.2012. "Tradisi Upacara Melasti Pada Masyarakat Hindu". Universitas Negeri Malang. http://karya-ilmiah.um.ac.id.

diunduh tanggal 26 Maret 2015.

Sudianta, I Putu, 2012. "Melasti (Upacara Ritual Masyarakat Hindu)". Universitas Negeri Gorontalo. http://eprints.ung.ac.id. diunduh tanggal 26 Maret 2015.

Sugiyono, 2009. Metode Penelitian Bisnis (Pendekatan Kuantitatif, Kualitatif, dan R\&D) .Bandung: Alfabeta.

---------, 2011. Metoda Penelitian Kombinasi. Penerbit Alfabeta Bandung.

Suhardana. Komang. 2010. Kerangka Dasar Agama Hindu, Surabaya: Paramita.

Suprayoga dan Tabroni.2011.Metodologi Penelitian Sosial-Agama. PT. Remaja Rosdakarya: Bandung

Suyono dan Hariyanto. 2011. Metode Penelitian. Jakarta: Pt Gramedia Widiarsana Indonesia.

Tim Penyusun.1995. Kamus Besar Bahasa Indonesia. Departemen Pendidikan dan Kebudayaan: Balai Pustaka. 
Jurnal Widya Sastra Pendidikan Agama Hindu, Vol 4, No. 1, 2021

ISSN: 2656-7466

Triguna, Yuda I B. 2000. Teori Tentang Simbol. Denpasar: Widya Dharma.

Wiana, 2002. Arti dan Fungsi Sarana Persembahyangan. Surabaya: Paramita. 